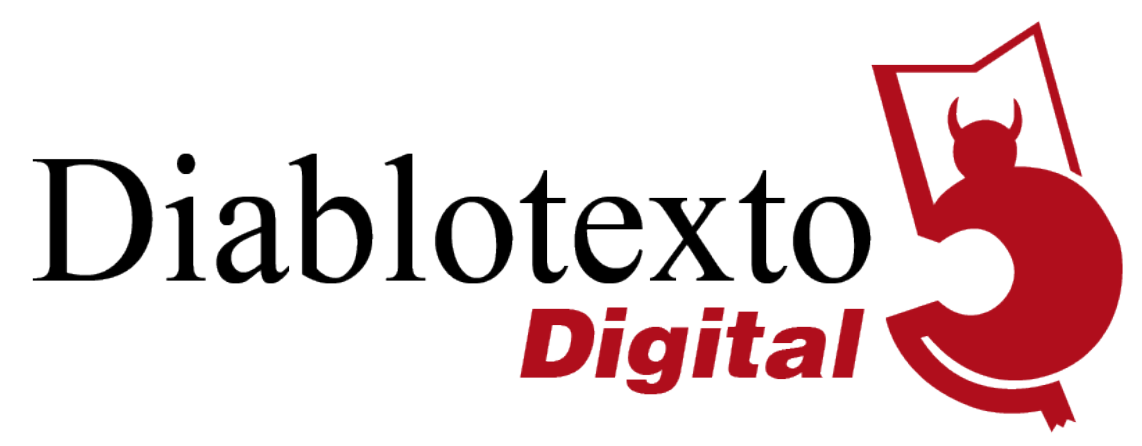

\title{
Gallegas en La Habana: memorias en femenino de emigración y exilio transatlánticos en Sol de Inverno de Rosa Aneiros
}

\author{
Galician women in Havana: Women's memories of emigration and exile in Sol \\ de Inverno by Rosa Aneiros \\ Diego Rivadulla Costa \\ UNIVERSIDADE DA CORUÑA
}

\begin{abstract}
Resumen: A lo largo de las dos últimas décadas, en el sistema literario gallego ha proliferado la narrativa de la memoria de autoría femenina. Al tiempo, se ha producido una importante diversificación del subgénero, que se refleja en una progresiva incorporación de las mujeres como protagonistas y de la perspectivización femenina de los relatos. Sol de Inverno (2009), la novela de Rosa Aneiros analizada en este artículo, constituye un ejemplo paradigmático de ello, al abordar el tema de la emigración y el exilio gallegos en Cuba centrándose en las vivencias de las mujeres, con el objetivo de recuperar su memoria y rendirles homenaje.
\end{abstract}

Palabras clave: narrativa gallega, Rosa Aneiros, memoria histórica, emigración, exilio

Abstract: In the Galician literary system of the last two decades, the narrative of female authorship has proliferated. At the same time, there has been a significant diversification of this sub-genre, which is reflected in the progressive incorporation of women as protagonists and in the feminine perspective in the stories. Sol de Inverno (2009), the novel by Rosa Aneiros analysed in this study, constitutes a paradigmatic example of all this. The author addresses the topic of Galician emigration and exile in Cuba, by focusing on the experiences of women, with the aim of recovering their memory and reclaiming them.

Key words: Galician narrative, Rosa Aneiros, historical memory, emigration, exile 


\section{Nuevas perspectivas en la narrativa gallega de la memoria: la emergencia de las mujeres}

A lo largo de los últimos veinte años, la denominada "narrativa de la memoria" ha ocupado, de manera progresiva, un lugar destacado en el ámbito de la creación literaria en lengua gallega. El aumento cuantitativo de obras publicadas desde el año 2000, los numerosos premios obtenidos por muchas de ellas, el éxito de ventas de algunos títulos y la atención crítica recibida por estos dan buena cuenta de ello. Así, desde finales de la década de los noventa del siglo pasado hemos asistido a la eclosión de un boom de memoria también en el campo de la narrativa gallega de ficción, enmarcado, a su vez, en el fenómeno social y cultural generalizado de recuperación de la memoria histórica que tiene lugar en Galicia, como en todo el Estado español, y que afecta tanto a la producción como a la recepción de novelas sobre la Segunda República, la Guerra Civil, el exilio o la dictadura franquista, entre otros temas. No se trata, pues, de un hecho singular del sistema literario gallego, sino común al conjunto de literaturas que conviven en el espacio pluricultural estatal, como constató Fernando Larraz para el caso de la narrativa española al señalar que, a partir del cambio de milenio,

la literatura se solidariza con un fenómeno general que se ha venido a denominar el boom de la memoria histórica. El corpus novelístico sobre la guerra se acrecienta, multiplicándose sus productos en el último decenio [...] y decanta la trayectoria de algunos escritores que habían velado sus primeras armas literarias en otros temas. (Larraz, 2014: 349)

En lo que a la dimensión autoral se refiere, existe consenso en que ha sido la generación de los conocidos como "nietos de la guerra" -aquellos nacidos a partir de los años cincuenta, no comprometidos con el pacto de la Transición- la responsable tanto del resurgir del pasado reciente en la esfera pública del siglo XXI como de su materialización literaria, en la que, no obstante, ya se habían implicado en las décadas anteriores algunos escritores pertenecientes a la generación de los hijos de la guerra -aquellos que, sin haber vivido la contienda en primera persona, crecieron en los años más oscuros de la posguerra-, con diferencias notables entre ambas, como ha 
analizado en profundidad la especialista Dolores Vilavedra (2011). Con todo, lo cierto es que, dada la magnitud del fenómeno, resulta especialmente llamativa la escasa presencia de mujeres en la amplísima nómina de autores de ambas generaciones que han optado por recuperar literariamente la memoria del golpe de Estado de 1936 o de la represión franquista. Aunque este hecho sí pueda explicarse, en parte, por ciertas singularidades sistémicas, pues fue en torno al año 2000 cuando el corpus denominado genéricamente "narrativa gallega de autoría femenina" experimentó una importante eclosión desde el punto de vista cuantitativo, aumentando considerablemente el número de obras y autoras (Vilavedra, 2018). Si exceptuamos el caso de María Xosé Queizán -y quizás de Chelo Suárez Muíños y Marilar Aleixandre, nacidas en 1945 y 1947, respectivamente-, quien se ha ocupado de manera recurrente del tema desde la perspectiva feminista que caracteriza toda su actividad literaria y extraliteraria, no es posible encontrar narradoras de la memoria pertenecientes a la generación de las hijas de la guerra, mientras que en el caso de la de las nietas encontramos únicamente los nombres de Pilar Buela, An Alfaya y Rexina Vega.

Conforme a lo anterior, si comparamos la producción narrativa memorialística de las dos últimas décadas con la de las anteriores, podemos afirmar que la autoría femenina no solo emergió para consolidarse a partir del cambio de siglo, sino que ha experimentado una proliferación constante en los últimos años. Tanto es así que en los años noventa solo contamos, entre la narrativa dirigida al público adulto, con la aportación de Queizán, pionera en el subgénero con Amor de tango (1992), con seguridad la más feminista de todas las novelas que trataron la República y el trauma del fascismo hasta el momento de su publicación (Thompson, 2009: 190), a la que habría que añadir algunas otras contribuciones a la memoria novelada de la guerra y del franquismo dentro del corpus de la literatura infantil y juvenil, como las escritas por Concha Blanco $-A$ misteriosa montaña da pena negra (1991)-, Marina Mayoral -Tristes armas (1994) - o Margot Chamorro -Tempo rachado (1999)-, que venían a sumarse a la precursora Chamábase Luís (1989), también de Mayoral. En contraste, a lo largo de la década de 2000, el incremento de Diablotexto Digital 8 (2020), 203-229 
narradoras y el auge de la cultura de la memoria se refleja en la publicación de numerosos títulos como: Teoría do caos (2001) de Aleixandre, Como hortensias no verán (2001) de Lola Roel, Sentinela, alerta! (2002) de Queizán, Ácaros verdes (2003) de Buela, A sombra descalza (2006) de Alfaya, Cardume (2007) de Rexina Vega o As horas rotas (2010) de Chelo S. Muíños ${ }^{1}$.

Aunque la mayor parte de los estudios en torno al tema contemplan únicamente las dos generaciones referidas, consideramos que a día de hoy sería conveniente distinguir aún una tercera, esta sí encabezada en su mayoría por mujeres escritoras que, a diferencia de los grupos anteriores, nacieron a mediados de los años setenta, la década de la muerte de Franco, y no habrían vivido la dictadura ni conservan un recuerdo consciente de la Transición, al haber crecido ya en la época democrática. Se trata, por tanto, de una unidad generacional conformada por un grupo de narradoras más jóvenes, entre las que destacan Susana Sánchez Arins, Inma López Silva, Rosa Aneiros, Eva Mejuto, Ledicia Costas o Patricia A. Janeiro, nacidas todas ellas entre 1974 y 1979 y cuya aparición en el panorama público literario no se produce hasta comenzados los 2000. Sin embargo, como anota Javier Lluch (2010: 59) al respecto de escritores españoles de esta generación como Isaac Rosa en relación con los nietos de la guerra -Muñoz Molina, Almudena Grandes o Chirbes-, aunque se distancien de los grupos anteriores en las expectativas vitales y los lenguajes estéticos, podemos afirmar ya que Arins, López Silva o Aneiros presentan intereses comunes y comparten con aquellos la responsabilidad social de la práctica literaria, también en lo que a la recuperación de la memoria histórica se refiere, como reflejan las obras que más adelante mencionaremos, que además se caracterizan por una progresiva incorporación de la perspectiva de género al tema. Si bien no entraremos ahora en ello, conviene mencionar que esa responsabilidad social se hace también

\footnotetext{
${ }^{1}$ Muchas de estas obras fueron, además, reconocidas y/o impulsadas con la concesión de importantes premios literarios como el Xerais (obtenido por Teoría do Caos y Cardume en 2001 y 2007, respectivamente), el Arcebispo Juan de San Clemente (con el que fueron galardonadas Ácaros verdes y Teoría do caos) o, en el caso de A sombra descalza, el Premio Lazarillo de Creación Literaria, el Premio Xosé Neira Vilas al Libro Infantil y Juvenil del año 2006 y el Premio The White Ravens (Internationale Jugend Bibliothek) al año siguiente.

Diablotexto Digital 8 (2020), 203-229
} 
patente, en muchos de los casos, en la dimensión extraliteraria, a través del compromiso público de las escritoras con causas diversas.

En relación con esto, debemos destacar que el relevo generacional y, en general, el boom narrativo de la memoria en Galicia trajo consigo una importante diversificación del subgénero. Esto favoreció, además, una evolución de las prácticas novelísticas desde el punto temático y formal. Aunque no es posible ofrecer aquí una caracterización pormenorizada de esta producción, para la que remitimos a Vilavedra (2011) o a alguno de nuestros trabajos previos sobre el asunto (Rivadulla Costa, 2019), sí debemos detenernos en algunos rasgos innovadores significativos en relación con la especificidad de este monográfico y que nos interesan para el análisis posterior. En primer lugar, es evidente que a la hora de acudir a la realidad histórica para retratarla, las autoras y autores del nuevo milenio parten de una memoria cada vez más indirecta y transmitida intergeneracionalmente en el ámbito privado, así como resultante de complejos procesos de documentación, es decir, de una "memoria prestada" (Gómez López-Quiñones, 2011: 114), recibida o construida, convirtiéndose el escritor, como señala Vilavedra (2011: 11), "en un mediador cuya función es iluminar con la luz del arte de la palabra el túnel de nuestra historia reciente para descubrir en él algunos de esos rincones ignotos que [...] la ficción puede ocupar".

En segundo lugar, mientras la narrativa previa se había ocupado fundamentalmente de tematizar el golpe de Estado del '36 y sus inmediatas consecuencias, la represión fascista y la resistencia antifranquista, la representación del exilio republicano y/o galleguista -tanto en Francia como en América Latina - va ganando espacio en la nueva novela de la memoria, desde nuevas perspectivas que en poco se asemejan a las autobiográficas de aquellos autores que habían vivido el destierro en primera persona y optaron por abordarlo literariamente, como Silvio Santiago o Ramón de Valenzuela. Asimismo, las tramas transnacionales que relacionan -implícita 0 explícitamente- el pasado propio con otras experiencias traumáticas como la de la Segunda Guerra Mundial son cada vez más abundantes, al lado de otros temas relacionados como la emigración gallega en Europa, Cuba o Argentina, Diablotexto Digital 8 (2020), 203-229 
que cuenta con destacados precedentes en la producción narrativa de Xosé Neira Vilas, entre otros. En relación con esto, la concepción del regreso a la tierra como un regreso al pasado, a través del personaje que vuelve a su lugar de origen y comienza a recordar y/o recuperar la memoria es un tópico que se repite en varias de las obras, funcionando incluso como mecanismo intradiegético que da acceso al pasado que se pretende narrar. La importancia de la emigración y el exilio en la historia de Galicia y, en consecuencia, su omnipresencia en la memoria y la identidad culturales gallegas explica en buena medida, sin duda, esta particularidad. La aparición de tal motivo en la trama narrativa está relacionada frecuentemente con el fallecimiento de los antepasados, en muchos casos de los progenitores, que motiva el regreso a Galicia y la recuperación de la memoria del destierro. Algunos ejemplos son $O$ exiliado e a primavera (2004) de Manuel Veiga, Memoria de cidades sen luz (2008) de López Silva, Monte Louro (2009) de Rei Núñez, Sol de Inverno (2009) de Aneiros o la reciente Sándalo (2019) de María Xosé Porteiro.

Finalmente, con respecto a los personajes, aunque la mayoría de protagonistas continúan siendo masculinos -huidos, guerrilleros, falangistas, víctimas o descendientes de estas-, la proliferación de la narrativa de la memoria de autoría femenina en el siglo XXI ha ido pareja a un progresivo aumento de la incorporación de mujeres como protagonistas de las historias y, asimismo, de la perspectivización femenina de los relatos. En contraste con la novela anterior al cambio de siglo, donde predominaban los héroes y víctimas masculinos, así como sus voces narrativas -con contadas y honrosas excepciones como la ya mencionada Amor de tango-, en los años 2000 asistimos a un cambio de paradigma que viene de la mano de títulos como Ten o seu punto a fresca rosa (2000) de la propia Queizán, Concubinas (2002) de López Silva, A perspectiva desde a porta (2009) de Patricia A. Janeiro, Seique (2015) de Sánchez Arins o Memoria do silencio (2019) de Eva Mejuto, que por lo general tienden a incorporar una perspectiva de género o feminista, de diversos modos y en diferentes medidas, en las historias ficcionalizadas. Pero para ser justos es preciso indicar también que la atención a las figuras femeninas en una narrativa que durante décadas había sido eminentemente Diablotexto Digital 8 (2020), 203-229 
masculina no solo fue propiciada por las nuevas autoras, sino también por numerosos escritores que comienzan a incorporar mujeres como protagonistas de sus obras memorialísticas -Non volvas (2000) de Suso de Toro o Era por setembro (2004) de Xabier Quiroga son ejemplos representativos- o como coprotagonistas y personajes con peso en la acción -en Expediente Artieda (2000) de Luís Rei Núñez o Non hai noite tan longa (2011) de Agustín Fernández Paz-, si bien es cierto que en muchos casos ellas siguen ocupando un papel secundario, de esposas, compañeras o amantes.

Sol de Inverno, la obra de Rosa Aneiros de la que nos ocuparemos en las líneas que siguen, no solo innova temáticamente al abordar la experiencia del exilio en relación con la emigración gallega en La Habana, sino que constituye un ejemplo paradigmático de ese nuevo discurso narrativo gallego de autoría femenina, marcado por un relevo generacional, que se ocupa de recuperar la memoria histórica de una manera consciente -y comprometida-, colocando el foco en las vivencias de ellas y narrándolas desde su propia perspectiva, desde una imperiosa "necesidade de reivindicar o papel de certas mulleres", como la propia autora declara en una entrevista realizada con motivo de este trabajo. Según sus propias palabras:

\begin{abstract}
Os nomes que máis pasaron ou as historias que máis transcenderon a nivel político foron de homes, pero a militancia política e o papel activo que mantiveron moitas mulleres, aínda despois de tantos anos, seguen escurecidos. Moitas mulleres si que foron grandes líderes, non foron sombras. Elas estiveron á sombra e iso si está traballado, [como é o caso] da muller de Alberti, da muller de Dieste, que foron mulleres que deixaron, digamos, que as luces caesen. Pero ollo coas historias delas. Traballaron moito pero se lles negou incluso ese papel de líderes, que iso é tremendo. É un ostracismo tremendo, porque se lles negou no seu día e se lles segue negando hoxe [...]. No caso da personaxe que eu construín non é así, pero no caso de outras moitas mulleres si se lles segue negando ese papel activo que tiveron e todo o que elas construíron. É unha cousa escandalosa².
\end{abstract}

\footnotetext{
2 "Los nombres que más han pasado o las historias que más han trascendido a nivel político han sido de hombres, pero la militancia política y el papel activo que mantuvieron muchas mujeres, todavía después de tantos años, siguen oscurecidos. Muchas mujeres sí fueron grandes líderes, no fueron sombras. Ellas estuvieron a la sombra y eso sí está trabajado, [como es el caso] de la mujer de Alberti, de la mujer de Dieste, que fueron mujeres que dejaron, digamos, que las luces cayesen. Pero ojo con las historias de ellas. Trabajaron mucho pero se les negó incluso ese papel de líderes, lo cual es tremendo. Es un ostracismo tremendo, porque se les negó en su día y se les sigue negando hoy [...]. En el caso del personaje que yo he construido no es así, pero en el caso de muchas otras mujeres sí se les sigue negando ese Diablotexto Digital 8 (2020), 203-229
} 


\section{Sol de Inverno: una historia de historias}

Con Sol de Inverno, Rosa Aneiros se hizo con el XXVI Premio Xerais de Novela en la edición correspondiente al año 2009, uno de los galardones más prestigiosos de la narrativa gallega en la actualidad. No obstante, la autora contaba ya en su haber con numerosos premios que avalaban su todavía no muy larga, pero sí exitosa, trayectoria como narradora en el sistema literario gallego $^{3}$. Si uno contempla el conjunto de su producción se dará cuenta, además, de que Sol de Inverno representa la consolidación de un proyecto creativo cimentado en un profundo interés por la historia reciente y, más concretamente, por rescatar las vivencias concretas de personajes que participan de acontecimientos socio-políticos de su realidad histórica próxima, combinando realidad y ficción a través de mecanismos que consiguen sembrar la duda en el lector sobre si es la primera la que está al servicio de la segunda o viceversa.

La primera muestra la encontramos en Resistencia (2003), una novela heredera del realismo crítico que participa en el discurso feminista posmoderno (Asorey Vidal, 2003) y que constituyó un éxito editorial que dio a conocer y consagró a Aneiros como narradora de referencia en el panorama literario gallego actual (Rivadulla Costa, 2016). Si en esta obra la autora evocaba la

papel activo que tuvieron y todo lo que ellas construyeron. Es una cosa escandalosa." [Traducción propia]. Estas declaraciones pertenecen, como mencionamos en el cuerpo del texto, a una entrevista realizada a la autora, a quien agradecemos muy sinceramente su colaboración, en Santiago de Compostela en julio de 2019 con motivo de la investigación que origina este artículo.

${ }^{3}$ Aneiros (Valdoviño, 1976) es probablemente una de las novelistas gallegas contemporáneas más premiadas, habiendo recibido más de una docena de galardones literarios a lo largo de las dos últimas décadas, entre los que destacan el Premio San Clemente en 2003 por Resistencia, el Antón Losada Diéguez de creación literaria en 2005 por Veu visitarme o mar, el Premio Agustín Fernández Paz de narrativa infantil y juvenil por la igualdad en 2018 o el reciente Premio Merlín de Literatura Infantil y Juvenil por Xelís, o guieiro das botellas de mar (2019). La autora no solo ha sido reconocida, por tanto, por su obra para adultos, sino que cuenta con una amplia producción narrativa dirigida al público juvenil, siendo una de las figuras de referencia en este campo.

Diablotexto Digital 8 (2020), 203-229 
represión de la dictadura salazarista portuguesa o la guerra colonial en Mozambique a través de una historia de amor y lucha política en la segunda mitad del siglo XX, y en su sucesora Veu visitarme o mar (2004) documentaba la catástrofe ecológica del petrolero Prestige en la Costa da Morte a comienzos del XXI, en Sol de Inverno opta por recuperar la memoria de la Segunda República en Galicia, la de la Guerra Civil española y, sobre todo, la del exilio republicano y galleguista, primero a Francia y después a Sudamérica, pero también la de la emigración gallega en Cuba, la de la revolución castrista e, incluso, la del mayo francés del '68. A través de la mirada de Inverno [Invierno], la narradora-protagonista, y a lo largo de más de quinientas páginas en las que se desarrolla la ficticia memoria personal y familiar de esta, Aneiros reconstruye fielmente cada uno de esos acontecimientos, mezclando personajes de ficción con un amplio elenco de personajes históricos como Rafael Dieste, Castelao o el Che Guevara, entre otros muchos, con los que los primeros interactúan y conviven en la resistencia, en la derrota $-\mathrm{y}$, aunque menos veces, en la victoria- y en el destierro.

Sol de Inverno está conformada por ocho grandes partes, divididas a su vez en un total de cincuenta y cuatro capítulos, las cuales se corresponden con cada uno de los lugares en que se desarrollan las diferentes etapas de la vida de la protagonista y de su familia. En este sentido, concordamos con Vilavedra (2009) en que se trata, como en el caso de sus contemporáneas Memoria de cidades sen luz o Monte Louro, de una novela nómade, cuyo personaje principal está condenado desde la cuna a un recorrido vital en la búsqueda de sí misma. La obra recrea la vida de Inverno desde su niñez y adolescencia en Antes hasta su regreso a esa ficticia aldea costera gallega con casi cincuenta años, en una estructura circular que pasa por Barcelona, Francia, México, Cuba y Argentina. No obstante, el primero y el último capítulo confluyen, en el mismo espacio y en el mismo nivel temporal, desde el que la narradoraprotagonista evoca su vida a través de un proceso de rememoración para el que cuenta con grandes dificultades y que, sin embargo, se vuelve necesario para su supervivencia, como declara en el capítulo 1, prólogo anunciador del viaje que se dispone a emprender: 
E mírate agora, Inverno, só deveces por lembrar. Por seguir existindo nas palabras que che vai perdoando esta intensa vida.

Comeza polas lembranzas primeiras. Serache máis doado. Vai amodiño, gorenta palabra a palabra, cada imaxe, cada son. Vai devagar, fai que perdure ese instante en que todo volve. Vai tirando do fío [...]. Farás que todo volva, se é que algunha vez marchou [...]. Agora, Inverno, só agarda lembrar. É o último facho que queda aceso para continuar vivindo. Volver a Antes ${ }^{4}$. (Aneiros, 2009: 13-14)

Como refleja la cita anterior, desde el punto de vista de la enunciación, la originalidad de la novela radica en el empleo de una voz en segunda persona, la de la propia Inverno, que se habla a sí misma a través de un largo monólogo que conforma el discurso de la obra. Los diálogos en estilo directo son escasos y la narradora autodiegética cede la palabra en contadísimas ocasiones, entre las que destacan fundamentalmente los monólogos de dos mujeres, la bisabuela materna Luzdivina y Carmen Muñoz Manzano, que constituyen sendos flashbacks que nos trasladan a la Cuba de entresiglos y a la época de la República en Antes, respectivamente. La focalización interna empleada a lo largo de la obra presenta dos particularidades que es preciso destacar: por un lado, hace posible que el lector, más allá de la narración histórica, tenga acceso en todo momento a los sentimientos y sensaciones que aquellos acontecimientos históricos provocaron en la protagonista; por otro lado, la visión que tenemos de los acontecimientos históricos está condicionada por la perspectiva de Inverno en el momento en que los vivió, buena parte de ellos -la guerra y la marcha al exilio, por ejemplo- siendo aún una niña adolescente de trece años. Aunque la reconstrucción vital esté realizada por la Inverno de cincuenta años regresada de Cuba, que se sitúa probablemente a comienzos de la década de los setenta para echar la vista atrás, no hay acción en ese nivel de la enunciación ni ninguna reflexión sobre ese plano temporal más contemporáneo ${ }^{5}$.

\footnotetext{
4 "Y mírate ahora, Inverno, solo deseas recordar. Seguir existiendo en las palabras que te va perdonando esta intensa vida. Comienza por los primeros recuerdos. Te será más fácil. Ve despacito, saborea palabra a palabra, cada imagen, cada sonido. Ve lentamente, haz que perdure ese instante en el que todo regresa. Ve tirando del hilo [...]. Harás que todo vuelva, si es que alguna vez se fue [...]. Ahora, Inverno, solo espera recordar. Es la última antorcha de luz que queda encendida para continuar viviendo. Volver a Antes." [Traducción propia].

${ }_{5}^{5}$ Aunque por la referencia a la edad de la protagonista sabemos que se trataría de comienzos de la década de los setenta, no hay ninguna marca que nos indique la localización temporal de los capítulos 1 y 55, desde la que Inverno recuerda.
}

Diablotexto Digital 8 (2020), 203-229 
En cuanto a su adscripción, parece pertinente incluir a Sol de Inverno en el género de la ficción histórica, siendo sus principales características la presencia $-\mathrm{y}$ el tratamiento riguroso- de personajes reales, documentados y transcendentes para la historia, la verdad de los acontecimientos referidos y la verosimilitud de personajes y hechos ficticios, como sucedía ya en su antecesora Resistencia (Rivadulla Costa, 2016: 129). Así pues, para Oriana Méndez (2009: 12), la narración remite "a algún relato de longo alento propio da novela do XIX", sucediéndose los hechos entre el tratamiento histórico, el romanticismo y la epopeya romántica, si bien parte de la crítica ha definido la obra en varias ocasiones como una novela de personaje (Vilavedra, 2010). Bajo nuestro punto de vista, solo lo es en el sentido en que la reconstrucción de la historia de Inverno discurre paralela a la configuración de su personalidad, de la que los lectores somos testigos, pero la protagonista ocupa con frecuencia un segundo plano en la acción, una posición testimonial. Su historia es, en el fondo, la historia familiar, la de cada uno de los miembros de su familia y la de los personajes - mayoritariamente femeninos- que con ella se relacionan, la de la resistencia galleguista en la Barcelona de la guerra, pero también la de las republicanas exiliadas y la de las gallegas y gallegos emigrados décadas atrás; es decir, la suya es una historia de historias. Convenimos, por tanto, con el crítico literario Alfonso Eyré (2009) en que Inverno nunca es la protagonista absoluta, ni de adolescente ni de adulta, ya que -al contrario que su padre- ella nunca se concibe como heroína, sino como hilo conductor y receptora de los acontecimientos que vive.

A pesar de que la novela recrea episodios históricos de transcendencia mundial localizados en diferentes países, es significativo que la perspectiva no deje nunca de ser, además de femenina, gallega. En primer lugar, porque la narradora-protagonista procede de una pequeña aldea de Galicia donde -y desde donde- inicia el relato de su vida. En segundo lugar, porque es a través de la rememoración de este personaje como se desarrolla toda la historia. En tercer lugar, porque entre los personajes con los que Inverno se relaciona en Barcelona, en el exilio francés y cubano o en el Ipanema, están siempre representados los gallegos y las gallegas, bien a través de figuras históricas 
que participan de la acción, como Rafael Dieste, Muñoz Manzano o Castelao, o bien de creaciones ficcionales como el amigo y combatiente Rafael, el bisabuelo Andrés, gallego emigrado a Cuba en el último tercio del siglo XIX, o la abuela Lola, que había desembarcado en La Habana con quince años obligada a prostituirse. Y, finalmente, porque, en consecuencia, la mayoría de los episodios que la protagonista narra está relacionada con las experiencias gallegas- de la emigración cubana en los siglos $\mathrm{XIX}$ y $\mathrm{XX}$, del núcleo de la resistencia galleguista al franquismo, de los gallegos que lucharon contra el nazismo en Francia después de haber estado confinados en los campos de concentración de Argelès-sur-Mer o Saint-Cyprien, o de los exiliados republicanos al otro lado del Atlántico, en Buenos Aires o en La Habana. Bien podríamos decir, en este sentido, que Sol de Inverno es una suerte de novela de la memoria gallega total, al estar conformada por muchos de los acontecimientos centrales de la Historia contemporánea de Galicia y, sobre todo, por episodios que conforman la microhistoria de sus habitantes.

Además de por la precisión en su base histórica y la precisa localización espacial y temporal, las ocho partes que componen la novela se caracterizan por su autonomía. También en este sentido Sol de Inverno es una historia de historias, pues cada una de esas grandes secciones cuenta con un elenco propio de personajes específicos, reales y ficticios, que acompañan a los principales -la protagonista, sus padres y su hermana Rebeca, que componen el núcleo familiar-y, como mencionamos unas líneas atrás, se desarrolla en un lugar con unas condiciones diferentes, por lo que podrían funcionar perfectamente como relatos autónomos. Los elementos paratextuales de la obra, por su parte, explicitan la base documental de la misma: en la dedicatoria a Silvia Mistral, Aneiros señala que fueron las notas de su diario -Éxodo. Diario de una refugiada española- $\mathrm{y}$, en menor medida, las memorias de otros exiliados como María Teresa León o Elixio Rodríguez, las que le permitieron recrear con fidelidad "a atmósfera e os sentimentos" (Aneiros, 2009: 9) de los seis meses de 1939 que Inverno pasa en Francia y en la cubierta del Ipanema. Además, la cita inicial en la que Rosita le pide al padrino que le cuente "el cuento de Cuba" remite al hecho, confesado por Aneiros en el discurso de Diablotexto Digital 8 (2020), 203-229 
agradecimiento del Premio Xerais, así como en numerosas entrevistas (Álvarez, 2009; Carballa, 2009), de que la parte cubana de la novela está basada en una fuente oral, la memoria de su padrino y, en concreto, las historias que este le contaba, siendo ella niña, sobre su emigración a La Habana. Esta memoria prestada constituye, de hecho, el germen de la novela, como reconoce la propia autora al ser preguntada por ello:

Eu levaba toda a vida querendo escribir a historia do meu padriño, a historia da emigración cubana. O meu padriño non ten nada que ver co que é a historia das personaxes [da novela]. Era católico, apostólico, romano; ía ca bandeira española na maleta e coa mantilla... non ten nada que ver. Pero foi unha maneira de que distintas teimas que había en min e distintas cousas que quería contar confluísen nunha soa novela. Por iso está moi presente a memoria. Non só a memoria histórica, a memoria da Guerra Civil, senón a propia memoria familiar, a propia memoria de meu padriño, porque a el colleuno a Guerra Civil en Cuba, entón, en certa maneira, eu non vivín a percepción de meu padriño na guerra porque [el] non estaba aquí. Esa percepción familiar da guerra non a tiña de meu, o que é a nivel de pouso familiar, pero si tiña Cuba. Eu creo que foi unha maneira de coller todos eses ingredientes, esas cousas que me importaban, e metinas nunha novela ${ }^{6}$.

\section{De Galicia a La Habana: memorias vivenciales de guerra, exilio y revolución}

La memoria vital de Inverno transmitida a lo largo de la obra, como señalamos en el apartado previo, está conformada por muchas otras memorias de personajes, lugares y acontecimientos históricos que nos llevan de lo personal a lo gallego y a lo universal a través del viaje internacional y transoceánico emprendido por la protagonista. La acción propiamente dicha comienza en 1936, con el retrato de la Segunda República y las inmediatas consecuencias de la sublevación militar del 18 de julio en la aldea de Antes, en

\footnotetext{
6 "Yo llevaba toda la vida queriendo escribir la historia de mi padrino, la historia de la emigración cubana. Mi padrino no tiene nada que ver con lo que es la historia de los personajes [de la novela]. Era católico, apostólico, romano; iba con la bandera española en la maleta y con la mantilla... no tiene nada que ver. Pero ha sido una manera de que diferentes obsesiones que había en mí y distintas cosas que quería contar confluyeran en una sola novela. Por eso está muy presente la memoria. No solo la memoria histórica, la memoria de la Guerra Civil, sino la propia memoria familiar, la propia memoria de mi padrino, porque a él lo cogió la Guerra Civil en Cuba, entonces, en cierto modo, yo no viví la percepción de mi padrino en la guerra porque [él] no estaba aquí. Esa percepción familiar de la guerra no la tenía por mí misma, lo que es a nivel de herencia familiar, pero sí tenía Cuba. Yo creo que ha sido una forma de coger todos esos ingredientes, esas cosas que me importaban, y las metí en una novela." [Traducción propia].
}

Diablotexto Digital 8 (2020), 203-229

doi: $10.7203 /$ diablotexto.8.18303 
la que el padre de la protagonista ejerce de alcalde, sigue con la huida y el establecimiento de la familia en la Barcelona de la guerra, marcada por los bombardeos diarios de la aviación italiana, y con el exilio francés a comienzos del '39, que constituyen, respectivamente, la segunda y tercera etapas del periplo de Inverno. Dada la extensión de la obra y teniendo en cuenta la especificidad de este trabajo, no profundizaremos aquí en la memoria de la contienda bélica ni del éxodo en Francia, sino que nuestro análisis se centrará, como se ha dicho, en las posteriores etapas de ese viaje vital, las constituidas por la experiencia cubana, y en la recuperación de la(s) memoria(s) histórica(s) de migración y exilio que la autora promueve a través de ellas.

El periplo francés, tras el paso por Argelès-sur-Mer y unos meses en Les Mages -situado en los límites de la Provenza-, donde Inverno y la familia son acogidas junto a otras refugiadas, termina con el reencuentro con el padre en Burdeos para embarcar en el famoso barco Ipanema con destino a México. La travesía del Ipanema a lo largo del mes de junio de 1939 constituye la cuarta etapa de las memorias de la protagonista y, como las anteriores, está conformada por episodios bien documentados que sucedieron a lo largo de aquel viaje histórico de casi un mes a través del Atlántico que vivieron cerca de mil refugiadas y refugiados españoles de la Guerra Civil y que Aneiros reconstruye con fidelidad. Debemos destacar, en este sentido, el homenaje a Galicia que las gallegas y gallegos embarcados realizaron el día 13 de junio en la cubierta del barco al pasar a la altura de Fisterra, leyendo una proclama a favor de la República y cantando el himno gallego. O, asimismo, la edición en el buque del boletín Ipanema: diario de a bordo, que recogía chistes, canciones y otros entretenimientos, pero también textos y recomendaciones sobre el futuro país de acogida, en el que la protagonista de la novela colabora ${ }^{7}$. Desde

\footnotetext{
${ }^{7}$ En el número inicial del diario, publicado el 14 de junio de 1939, aparece una breve crónica de ese acto al que aludimos, titulada "Frente a Finisterre", en la que se recoge el texto leído a modo de proclama por los viajeros gallegos que conformaban el pasaje y que Aneiros reproduce en la novela. Los veintiséis números editados del Ipanema entre el 14 de junio y el 18 de julio del 39 se encuentran digitalizados y disponibles para su consulta en la Biblioteca Virtual Miguel de Cervantes a través del siguiente enlace: http://www.cervantesvirtual.com/nd/ark:/59851/bmcjh5f7 [Fecha de consulta: 10 de septiembre de 2020].
} 
nuestro punto de vista, la narración de tales acontecimientos constituye, en términos de Elina Liikanen (2015), un modo vivencial de memoria, que se caracteriza "por representar el pasado como una experiencia vivida", transportando al lector a ese pasado "para hacerle compartir la experiencia subjetiva de los protagonistas" (Liikanen, 2015: 116-117), y que será predominante a lo largo de toda la obra.

Inverno va recordando anécdotas del millar de pasajeros -“un universo de covardes e de afoutos guerrilleiros, de miñaxoias e de valentes republicanas" (Aneiros, 2009: 272)- que huyeron en busca de la libertad al "otro lado", consiguiendo que los lectores podamos revivir, de manera vicaria, la experiencia de aquellos días que duró la travesía. Entre esas valientes republicanas surge la figura de Carmen, cuyas conversaciones con la protagonista nos remiten, a través del recuerdo, al momento en que ambas se habían conocido años atrás con motivo del viaje de la primera a Antes en la comitiva de las Misiones Pedagógicas, junto a Rafael Dieste y otros intelectuales del momento. Los extensos monólogos de Muñoz Manzano, a quien Inverno cede por completo la palabra, concentran la memoria nostálgica de aquel ilusionante proyecto cultural y educativo que tan bien representa los valores y el espíritu de la fracasada República, contraponiéndose a la incertidumbre ante lo que les espera en la otra orilla, y ocupando la mayor parte de la sección de la novela dedicada al periplo transatlántico, que termina con la recreación del festivo recibimiento con honores cuando el barco con los asilados políticos españoles atraca en el puerto de Veracruz, el 7 de julio de 1939. Si la travesía representa un punto de inflexión para los personajes, la recepción oficial por parte del gobierno de Lázaro Cárdenas constituye el optimista prólogo de la acogida a los exiliados por parte de los diferentes países de América Latina a los que se dirigen -mientras Carmen parte de inmediato a Uruguay, por ejemplo, la familia de Inverno lo hace a Cuba- y contrasta con el recibimiento que habían tenido en Francia: la impactante imagen de las bombas con que los despidió Cataluña y de los gritos de desprecio de las autoridades galas a su llegada al país vecino se contrapone 
con la de los vítores y brazos abiertos del pueblo mexicano, que las consideraba heroínas.

La quinta etapa de la vida de la protagonista comienza, por fin, con la llegada a La Habana, donde su padre y su madre habían nacido y de donde se habían marchado casi dos décadas atrás, retornando ahora como exiliados. La etapa cubana está marcada por el descubrimiento de una apasionante historia familiar, por la convivencia con los abuelos maternos Lola y Ezequiel -gran empresario del negocio del tabaco y en aquel momento uno de los hombres más ricos de la ciudad-y, sobre todo, por el paso de Inverno a la edad adulta. La inadaptación a la lujosa mansión de Villa Estrella y la mala relación con los abuelos favorecen que la protagonista establezca una relación especial con Luzdivina, su bisabuela, con la que pasa los días visitando la tumba del marido de esta en el cementerio de Colón. A través de los largos monólogos de la anciana, a quien todos consideran enloquecida, es cómo Inverno -y al tiempo el lector- conoce, por un lado, la historia del bisabuelo, emigrante gallego, amigo de José Martí y colaborador activo de la insurrección cubana en la Guerra de la Independencia de 1898; por otro, la historia de los mencionados abuelos maternos, pero también la de los paternos, Mercedes y Lino emigrantes gallegos igualmente, periodistas y defensores de los más desfavorecidos, cuya ideología contrasta con la de los conservadores Lola y Ezequiel-; e incluso la historia de Alfredo, el padre de la protagonista, participante en las revueltas universitarias en La Habana de comienzos de los años veinte junto al revolucionario comunista -por aquel entonces líder estudiantil- Julio Antonio Mella, antes de marcharse a Galicia.

No obstante, las revelaciones de la bisabuela cubana van mucho más atrás en el tiempo, retrotrayéndose a la historia de Cuba desde el siglo XVI, a las hazañas del famoso pirata Diego Grillo y a las tribus de esclavos africanos que conforman sus raíces. Además, a lo largo de los monólogos de Luzdivina, Sol de Inverno rastrea la presencia de Galicia en la isla desde el siglo XIX, refiriéndose incluso a la famosa Expedición Balmis que pretendía llevar la vacuna de la viruela hasta América Latina y que contó con la participación de veintidós niños del hospicio de A Coruña, capitaneados por la coruñesa Isabel 
Cendal, cuya historia narraría por extenso años después la escritora María Solar en la premiada Os nenos da varíola (2017) y cuya figura ha comenzado a ser reivindicada solo de manera muy reciente, tras las investigaciones de López Mariño (2018) ${ }^{8}$. Con todo, lo más original, e innovador en relación con el corpus previo de literatura de tema migratorio hecha en Galicia (Vilavedra, 2018: 182), resulta esa genealogía familiar que traza Aneiros con vistas a recuperar minuciosamente la memoria colectiva de la emigración gallega, la del ascenso de los grandes propietarios tabaqueros y de sus esclavos, la del negocio de la trata de blancas o la del Centro Gallego de La Habana, sus luchas internas, los conflictos políticos que se producen en su seno y las vivencias que giran en torno a él, algunas de las cuales serían ficcionalizadas también por Porteiro unos años después en la ya mencionada Sándalo.

La muerte de Luzdivina constituye el final de la primera y más detallada parte de las memorias habaneras de Inverno. A partir de ahí, la protagonista comienza a estudiar y a trabajar en el Diario de la Marina, periódico conservador de referencia en la ciudad que había sido fundado por el gallego Isidoro Araújo de Lira, al tiempo que escribe clandestinamente para la revista Loita, portavoz de los gallegos antifranquistas en la isla, donde Inverno da voz a Castelao, Roberto Blanco Torres o Xosé Rubia Barcia, aquellos "amigos de papá que perderan a guerra, uns na distancia da emigración e outros na perda no exilio" (Aneiros, 2009: 409-10), intelectuales de cuyos textos Aneiros insiere algún fragmento en la novela. Avanzando en el tiempo, en 1946, tras el fin de la guerra en Europa, regresa Alfredo a Cuba e Inverno decide no separarse nunca más de él. El padre comienza a adquirir así un mayor protagonismo, contándole a su hija su lucha contra el fascismo como miembro de la Novena Compañía que había liberado a París en el 1944. A través de estas vivencias, la autora introduce también, aunque de manera lateral, la memoria de la

\footnotetext{
${ }^{8}$ Además de la obra de Solar, conviene mencionar la novela en español $A$ flor de piel (2015) de Javier Moro, que reconstruye la historia de Zendal, así como la película 22 ángeles, dirigida por Miguel Bardem y producida por TVE en 2016 a partir de la novela homónima de Almudena de Arteaga. Recientemente, Henrique Mariño ha publicado un completo reportaje sobre la figura de la enfermera en el diario Público, que puede leerse en el siguiente enlace: https://www.publico.es/sociedad/isabel-zendal-enfermera-vacuna-viruela.html.

Diablotexto Digital 8 (2020), 203-229
} 
Segunda Guerra Mundial y, específicamente, el homenaje a los tres mil doscientos españoles, muchos de ellos veteranos de la Columna Durruti, que junto al padre de Inverno habían sido "os salvadores de Europa" (Aneiros, 2009: 423).

La muerte de Alfonso Daniel Rodríguez Castelao en el exilio argentino en 1950 constituye un punto de inflexión simbólico en la historia cultural gallega $y$, al tiempo, en la diégesis ficcional: es el episodio central que da comienzo a una nueva etapa en la vida de la protagonista, quien viaja con su padre desde Cuba a Buenos Aires para el entierro del eminente escritor, artista y político. La visita al panteón del Centro Gallego en el Cementerio de la Chacarita y el reencuentro con Carmen Muñoz y otros exiliados en el café Tortoni evidencian el fin de una época en lo que a la resistencia política galleguista se refiere. Esta constatación provoca que Alfredo, a su regreso a La Habana, se involucre por completo en la lucha de la guerrilla que pretende derrocar la dictadura de Batista, recuperando Aneiros la memoria de la revolución castrista. La función testimonial que la autora otorga a Inverno en estos acontecimientos llega hasta el punto de ser ella, en su papel de periodista, quien convenza y acompañe a la corresponsal Ruby Hart Phillips -en lugar de a su colega Herbert Matthews- a realizar la histórica entrevista a Fidel Castro en Sierra Morena publicada en The New York Times en 1957 (Calvo, 2017) $^{9}$. El padre de la protagonista, ante la atenta mirada de su hija, contribuye entre otros gallegos a la victoria de la revolución cubana en 1959, junto a Castro y al Che Guevara, del que se vuelve inseparable. El asesinato de este será, de hecho, un duro golpe para Alfredo, que cae enfermo en el momento en que surgen las revueltas estudiantiles en el París del '68, seguidas por él con interés y emoción.

El viaje a París para cumplir el último deseo del padre y presenciar otro hecho histórico victorioso constituye la última etapa del viaje de Inverno. Alfredo muere en un hospital de la capital francesa y la protagonista deambula

\footnotetext{
${ }^{9}$ En realidad, tal y como explica Calvo (2017: 179-181), la entrevista al líder revolucionario fue realizada por el periodista Herbert Matthews, que viajó a Cuba para tal fin, aunque el papel de Phillips, corresponsal de The New York Times en la isla desde los años treinta y pionera en el oficio, fue determinante en la organización de la operación y, en general, en la cobertura informativa de la insurrección cubana para los Estados Unidos.
} 
por las calles de la ciudad al tiempo que aparecen en ella los primeros síntomas de Alzheimer, enfermedad que había padecido también su bisabuela. Ante la consciencia de que está perdiendo la memoria y el temor a perder la noción de sí misma, decide volver a Antes, al punto de partida, para recordar.

\section{La representación y reivindicación de las mujeres transatlánticas}

En gran medida, Sol de Inverno constituye un homenaje a la Segunda República y, más específicamente, a la generación que la hizo posible y que luchó por no perderla. Alfredo y los históricos intelectuales galleguistas que se relacionan con él representan la inteligencia, la dignidad, la libertad, la razón y la democracia frente a la violencia, la sinrazón y el totalitarismo, tanto del franquismo como de los fascismos europeos y de la dictadura cubana de Batista. Así, a medida que avanza, la obra se erige en una novela de memoria transnacional, abarcando experiencias de ambos lados del Atlántico y respondiendo al patrón de memoria cosmopolita, que se caracteriza, entre otros rasgos, por colocar el foco en la experiencia de las víctimas y por presentar una visión dicotómica del mundo basada en la aplicación de las categorías del "bien" y del "mal" a los conceptos abstractos de democracia y totalitarismo (Hansen, 2015, 2016). La correlación que la autora establece entre la guerra española y la Segunda Guerra Mundial, bien como la presentación de la resistencia al fascismo en Europa y de la disidencia cubana como una misma causa única facilitan esta visión cosmopolita del pasado ${ }^{10}$.

Pero lo más destacable resulta -también por poco frecuente en la narrativa memorialística gallega hasta ese momento- el hecho de que las mujeres ocupen una posición central en ese homenaje generacional republicano que Aneiros realiza a través de las palabras de Inverno. Sol de Inverno recupera una memoria en buena parte femenina, no solo por contar con una narradora-protagonista sino sobre todo por rescatar las historias de mujeres que formaron parte de los acontecimientos ficcionalizados,

\footnotetext{
${ }^{10}$ Esto se hace explícito, por ejemplo, en las siguientes palabras de la narradora: "a loita, insistía papá, era universal, moito máis alá da pequenez de miras das fronteiras e dos estados" (Aneiros, 2009: 470).

Diablotexto Digital 8 (2020), 203-229
} 
constituyendo un contradiscurso al olvido al que han sido sometidas. Asumiendo una función de alternativa al relato hegemónico, la novela pretende visibilizar el papel de ellas y otorgarles un primer plano, a menudo a costa de los hombres, que eran quienes habían venido ocupándolo, como sucede con el caso de Matthews y Phillips, la corresponsal de prensa estadounidense mencionada unas líneas atrás. Carmela, la madre de Fiz, la maestra Carla o la amiga Laura, víctimas de la sublevación fascista en Antes, Mercé, experta en conseguir comida en la Barcelona sitiada, su nieta Silvia, víctima de los bombardeos militares, la comunista Isabel y las demás mujeres que pujan por sobrevivir en el éxodo francés y sacan adelante a sus familias mientras sus maridos están retenidos en los campos, Luzdivina, las abuelas Mercedes y Lola o su madre Felicia son algunos de los personajes femeninos con los que la protagonista convive a lo largo de su periplo vital y que, por otra parte, contribuyen a conformar su identidad. Las historias trágicas de todas ellas, que la narradora relata, movida por la empatía y la admiración mucho más que por la compasión, son también parte de la historia de Inverno, para quien la despedida de cada una de ellas representa, además, el final de cada etapa.

Entre estas mujeres destacan aquellas que presentan una identidad transnacional o para las cuales la vivencia transoceánica constituye un elemento definitivo en su construcción identitaria. Es el caso, como se ha dicho, de Carmen Muñoz Manzano, descrita por Portela Yáñez (2012) como una "activista cultural nas dúas beiras do Atlántico". Esta extremeña de origen y gallega de adopción, además de como maestra, ejerció como inspectora de enseñanza primaria y con la llegada de la República colaboró en las Misiones Pedagógicas. Durante la guerra destacó por su actuación en defensa del régimen republicano y tanto en ese período como en el exilio -un largo periplo de veintidós años que abarca París, Buenos Aires, Cambridge o Monterrey hasta que retorna a España en el '61- continuó desarrollando labores pedagógicas y divulgativas, participando en publicaciones culturales, con frecuencia bajo el pseudónimo de Beatriz Galindo (Portela Yáñez, 2012). No obstante, su figura se ha visto con el tiempo relegada a un segundo plano ante la importancia que adquirió la de su marido, el escritor Rafael Dieste, a cuyo Diablotexto Digital 8 (2020), 203-229 
legado literario dedicó además Muñoz buena parte de su vida. Lo que hace Aneiros es revertir esta injusticia histórica poniendo en valor la figura de la segunda y otorgando un papel secundario al primero. Por un lado, la autora adopta el pseudónimo ocasionalmente empleado por Dieste a lo largo de su carrera para referirse a su personaje a lo largo de toda la novela, de modo que el intelectual gallego aparece siempre representado como Félix (Muriel), mientras que su mujer, por el contrario, aparece con el nombre real de Carmen, y nunca como Beatriz. Por otro lado, la reivindicación de esta pasa, como se ha dicho, por concederle la palabra para que narre la experiencia republicana desde su punto de vista, privilegio reservado a muy pocos personajes en Sol de Inverno. Y, finalmente, el mejor homenaje viene del retrato que Inverno hace de la maestra extremeña, que denota una profunda admiración por ella. La "dura, afouta e imbatible Carmen", la "esperanza irreversible do seu rostro", su "elegancia e dignidade" y su "fortaleza inexpugnable" le recuerdan a la protagonista a otras mujeres republicanas que había visto (Aneiros, 2009: 281), de las que Muñoz se erige en exponente simbólico o metonímico.

Con respecto a las mujeres que protagonizan la etapa cubana, además de Inverno y su hermana menor Rebeca, adquieren un peso significativo aquellas otras que conforman la genealogía familiar. Por una parte, Felicia, la madre de ambas, que regresa con ellas a su tierra natal, de la que había huido por amor a Alfredo en 1922, cuando tomó el mismo barco hacia Galicia que él, cruzando el Atlántico y engañando a sus padres. Tras unos años de felicidad juntos, otro barco en una nueva travesía transoceánica la había traído de vuelta, huyendo de nuevo, aunque por otros motivos bien distintos, y obligándola a reencontrarse con su familia, la cual se había jurado no perdonarla jamás. La actitud de sacrificio y resignación que muestra la madre de la protagonista -también por amor- ante las permanentes ausencias de Alfredo y las penurias sufridas en Barcelona o Francia contrasta con su orgullo en el episodio de la llegada al puerto de La Habana, donde gracias a su carta de ciudadanía pueden desembarcar sin impedimentos, a diferencia de lo que le ocurre a la mayoría de emigrantes. Por primera vez, como recuerda Inverno, "mamá sentiu que facía algo pola familia. Que era ela quen nos salvaba e non Diablotexto Digital 8 (2020), 203-229 
a misericordia allea" (Aneiros, 2009: 189). Para Felicia, personaje en cuyo germen parece encontrarse la figura simbólica de la viuda de vivo, modelo fundacional de la espera (Garrido, 2015), este viaje de vuelta supone en cierta medida un renacer, el regreso a una vida a la que hacía años que había renunciado, aunque su identidad esté ya para siempre marcada por las traumáticas experiencias sufridas al "otro lado" del océano.

Si la oposición entre la figura materna, quien reniega de la militancia política y acaba aceptando una vida condicionada por este hecho, y la paterna, que representa el compromiso inquebrantable con los ideales democráticos, es una constante a lo largo de toda la novela, en la etapa cubana el contraste encuentra su particular paralelismo en las madres de ambos: las abuelas de la protagonista, Lola y Mercedes, cuyas biografías conocemos a través de los monólogos de Luzdivina. A través de la primera, Aneiros refleja la realidad de tantas chicas solteras de procedencia humilde que comenzaron a emigrar solas a Cuba tras la Guerra de la Independencia y acabaron en manos de proxenetas, algo que venía ocurriendo ya desde el siglo XIX (Cagiao, 2007: $81)^{11}$. Como otras gallegas, la abuela materna de Inverno llegó a la isla con solo quince años, la obligaron a prostituirse y se enamoró de uno de sus clientes, un señorito de una de las principales familias que frecuentaban el Centro Gallego de La Habana, que la maltrató, la dejó embarazada y acabó casándose con ella, con el objetivo de tener hijos "blancos". Lola decidió olvidar sus orígenes y que un día había atravesado el charco en busca de una vida mejor, abandonó a sus amigas de la emigración y cambió su ropa y su acento, con la intención de integrarse en la alta sociedad cubana.

Por el contrario, Mercedes, la madre de Alfredo, originaria de Antes, la idílica aldea gallega donde Inverno pasa su infancia, ejerce profesionalmente el periodismo y aparece caracterizada como un personaje comprometido con los derechos de las mujeres inmigrantes, a las que prestaba ayuda y cuyo

\footnotetext{
${ }^{11}$ Muy recientemente se ha estrenado un documental, dirigido por Xosé Lois Santiago "Pello" y Fran Naveira, que bajo el título Hijas de Galicia, Macorinas retrata la explotación a la que se vio sometida una parte de la emigración femenina gallega a Cuba a comienzos del siglo pasado, un hecho del que especialistas como la citada Pilar Cagiao se habían ocupado con anterioridad desde el ámbito historiográfico.
}

Diablotexto Digital 8 (2020), 203-229 
sometimiento se ocupaba de denunciar. Tanto es así que, en el pasado, el personaje se había preocupado por la situación de vulnerabilidad en que vivía la que más tarde sería su consuegra, aunque una vez que el destino las unió de nuevo, Lola actuó como si no la conociese. La discriminación de género que existía en el ámbito institucional del Centro Gallego de La Habana, creado en 1879, hace que las compatriotas gallegas en la isla comiencen a organizarse, lideradas por algunas pioneras feministas como Andrea López Chao, tal y como la ya mencionada novela Sándalo se encarga de retratar. De esta forma surge la sociedad Hijas de Galicia, constituida en Cuba en 1917 con el objetivo de dar asistencia a las miles de mujeres emigrantes que a comienzos del siglo XX llegaban desamparadas desde el otro lado del Atlántico (González Pagés, 2003) y que constituye uno de los gérmenes del amplio movimiento asociativo femenino que crece a partir de los años veinte en la sociedad cubana. Aunque Aneiros no se detiene en describir el desarrollo del mismo, el personaje de Mercedes, que probablemente se trate de un tributo a la olvidada figura de la periodista gallega Mercedes Vieito Bouza (Cabido, 2001), representa ese feminismo incipiente con el que Inverno pronto se identifica. De hecho, la protagonista de la novela acaba siendo "rescatada" de Villa Estrella por la abuela materna y sigue sus pasos dedicándose al periodismo gracias a la ayuda de esta.

Con todo, el personaje con quien más se siente identificada Inverno y que más contribuye a la construcción de su identidad durante su etapa en Cuba es Luzdivina. La historia de la anciana, de quien la protagonista parece heredar el Alzheimer, por un lado, simboliza que la pérdida definitiva de la memoria provoca la desaparición -en este caso la muerte- y, por otro lado, refleja la importancia de las portadoras de memoria, de exteriorizar y transmitir el legado a otras para que perdure. Las palabras del doctor constatan esto en el momento en que la bisabuela comienza a degenerar más rápidamente con la llegada de su sucesora:

Luzdivina, a filla do Dieguillo só agardaba por ti, Inverno, só agardaba por ti. Ela é da tribo do palenque de cimarróns, das mulleres liberadas da escravitude por un pirata, das roubadas a África polos negreiros que quixeron explotar a súa man de obra. 
Luzdivina é a derradeira muller viva, Inverno, e elas foron educadas para transmitir a memoria. [...] Por fin atopou a quen deixar o seu herdo. Para a súa estirpe a memoria éo todo e foi un milagre que ti puideses regresar ${ }^{12}$. (Aneiros, 2009: 388)

La protagonista hereda de esta otra mujer transatlántica que se presenta como descendiente de las esclavas africanas la dolencia cognitiva al mismo tiempo que recibe la memoria colectiva de siglos con la que la anciana cargaba, herencia que la libera definitivamente. Inverno se convierte, así, en portadora de la memoria secular de Cuba, al igual que a lo largo de su periplo vital de ida y vuelta a través de un océano había actuado como portadora de la memoria de los diferentes personajes que hemos mencionado y que la acompañan en sus diferentes etapas. La correspondencia que mantiene hasta alcanzar la madurez con Laura, su amiga de la infancia en Antes, representa un hilo invisible que la conecta permanentemente con el lugar de origen, aunque este se encuentre en la otra orilla del Atlántico. La estructura circular de la novela, que termina en el mismo lugar y con las mismas palabras con las que comienza, incide en la importancia de recordar lo mismo una y otra vez, así como en la existencia de un binomio memoria-vida. Mientras el viaje vital debe ser interpretado en relación con la metáfora clásica en la literatura gallega de autoría femenina sobre la construcción de la identidad (López Sández, 2016), el discurso de la narradora, enferma de Alzheimer, constituye una lucha contra el olvido y su enfermedad funciona como metáfora de la desmemoria colectiva que como sociedad sufrimos. A través de la necesidad que Inverno siente de recordar para saber quién es, manifestada especialmente en esos primer y último capítulos de la novela, Aneiros formula la relación de dependencia entre memoria e identidad, la necesidad de recordar -y contar- para ser en el presente y pervivir en el futuro.

\footnotetext{
12 "Luzdivina, la hija de Dieguillo solo esperaba por ti, Inverno, solo esperaba por ti. Ella es de la tribu del palenque de cimarrones, de las mujeres liberadas de la esclavitud por un pirata, de las robadas a África por los negreros que quisieron explotar su mano de obra. Luzdivina es la última mujer viva, Inverno, y ellas fueron educadas para transmitir la memoria. [...] Por fin encontró a quien dejar su herencia. Para su estirpe la memoria lo es todo y fue un milagro que tú pudieses regresar." [Traducción propia].
}

Diablotexto Digital 8 (2020), 203-229 


\section{Conclusión}

Como hemos tratado de reflejar a lo largo del análisis, Sol de inverno representa un cambio de paradigma en la narrativa gallega de la memoria del siglo XXI, caracterizado por el protagonismo de las mujeres. La magna novela de Aneiros constituye un relato de la Historia contemporánea desde una perspectiva gallega y femenina que reivindica a quienes lucharon por la República y se exiliaron cuando la perdieron, así como a quienes sufrieron la experiencia migratoria. A través de la mirada de la narradora-protagonista, la autora elabora un contradiscurso que tiene como objetivo recuperar, a través de múltiples referencias a una realidad histórica silenciada, la memoria de aquellas mujeres transatlánticas cuyas identidades van conformando la del personaje principal a lo largo de la obra. Afectada por la enfermedad del olvido, la protagonista se ve condenada a un viaje eterno de ida y vuelta entre Galicia y La Habana, de uno a otro lado del océano, a través del recuerdo, para seguir existiendo.

\section{Bibliografía}

Álvarez, Natalia (2009). "Entrevista. Rosa Aneiros". Faro da Cultura. Faro de Vigo, 05-09-2009.

AneIros, Rosa (2009). Sol de Inverno. Vigo: Xerais

ASOREY VIDAL, Daniel (2003). "Apuntamentos sobre dúas narradoras. Para unha tentativa de clasificación e lectura de Concubinas, de Inma López Silva, e Resistencia, de Rosa Aneiros", Anuario de estudos literarios galegos, 2003, pp. 9-15.

CABIDO PÉREZ, Puri (2001). "Un nome para rescatar do olvido: Mercedes Vieito Bouza", Andaina. Revista galega de pensamento feminista, n. ${ }^{\circ} 28$, pp. 53-56.

CAGIAO VILA, Pilar (2007). "A muller galega na emigración a Cuba e Arxentina (1870-1930)". En Helena González y María Xesús Lama (eds.), Mulleres en Galicia. Galicia e os outros pobos da península. Actas do VII Congreso Internacional de Estudos Galegos. Sada (A Coruña): Ediciós do Castro, pp. 77-92.

Calvo GonzÁlez, Patricia (2017). "El interés por la insurrección cubana (19531958) en Estados Unidos: The New York Times como medio influyente", Historia y Comunicación Social, 22 (1), pp. 173-190.

Carballa, Xan (2009). "Á literatura só lle pido o pracer de escribir as historias que me fascinan", A Nosa Terra, 1.384, p. 27. 
EYRÉ, Xosé Manuel (2009). "De como se conforma unha personalidade". $A$ Nosa Terra, 1.380, p. 28.

GARRIDO, Ana (2015). "Viudas de vivos: la representación desde el exilio gallego de la vulnerabilidad y la violencia en el cuerpo y el rostro de la mujer que espera, a partir de la obra de Luis Seoane y Alfonso Daniel Rodríguez Castelao". En Miguel Carrera Garrido y Mariola Pietrak (coords.), Violencia y discurso en el mundo hispánico: género, cotidianidad y poder. Sevilla: Padilla Libros, pp. 251-270.

GómEZ LóPEZ-QUIÑONES, Antonio (2011). "La misma guerra para un nuevo siglo: textos y contextos de la novela sobre la guerra civil". En Palmar Álvarez-Blanco \& Toni Dorca (eds.), Contornos de la narrativa española actual (2000-2010). Madrid: Iberoamericana-Vervuert, pp. 111-119.

GónZÁlez PAGÉs, Julio César (2003). Emigración de mujeres gallegas a Cuba. Las Hijas de Galicia. Vigo: Concello de Vigo.

HANSEN, Hans Lauge (2015). "Formas globales e historias locales. Influencias transnacionales en la narrativa actual sobre la guerra civil". En Juan Carlos Cruz Suárez, Hans L. Hansen y Antolín Sánchez Cuervo (eds.), La memoria novelada III. Memoria transnacional y anhelos de justicia. Berna: Peter Lang, pp. 123-150.

HANSEN, Hans Lauge (2016). "Modes of Remembering in the Contemporary Spanish Novel", Orbis Litterarum, 71 (4), pp. 265-288.

LARRAZ, Fernando (2014). "La guerra civil en la última ficción narrativa española", Studia historica, 32, pp. 345-356.

LIIKANEN, Elina (2015). "La novela como viaje al pasado: El modo vivencial de representar la Guerra Civil y la dictadura franquista en la novela española actual". En Hans Lauge Hansen y Leonardo Cecchini (eds.), Conflictos de la memoria / memoria de los conflictos. Modelos narrativos de la memoria intergeneracional en España e Italia. Copenhagen: Museum Tusculanum, pp. 114-125.

LLUCH PRATS, Javier (2010). "El concepto de generación en la construcción de la historia de la novela española contemporánea: entre el pasado reciente y un futuro posible". En Raquel Macciuci y María Teresa Pochat (eds.), Entre la memoria propia y la ajena. Tendencias y debates en la narrativa española actual. La Plata: Ediciones del lado de acá, pp. 51-75.

LóPEZ MARIÑo, Antonio (2018). Isabel Zendal Gómez en los archivos de Galicia. Santiago de Compostela: Parlamento de Galicia.

LÓPEZ SÁNDEZ, María (2016). "Women's Mobility in Contemporary Galician Literature: From 'Widows of the Living' to 'I Too Wish to Navigate'”. En María Jesús Lorenzo-Modia (ed.), Ex-Sistere: Women's Mobility in Contemporary Irish, Welsh and Galician Literatures. Newcastle: Cambridge Scholars, pp. 10-26.

MÉndEZ, Oriana (2009). "A magnitude do inverno". Tempos Novos, "Protexta", 12, 14.

Portela YÁñez, Rosario (2012). "Carmen Muñoz Manzano. Activista cultural nas dúas beiras do Atlántico", en <http://culturagalega.gal/album/detalle.php?id=295> [Fecha de consulta: 10 de septiembre de 2020]. 
Rivadulla Costa, Diego (2019). "(Des)memoria cultural e ficción literaria: o caso da narrativa galega actual sobre o franquismo". En Núria Codina Solà y Teresa Pinheiro (eds.), Iberian Studies: Reflections across Borders and Disciplines. Berlin: Peter Lang, pp. 233-253

RivadulLA Costa, Diego (2016). "O «real/histórico» ao servizo da ficción. Usos da Historia e da realidade en Resistencia, de Rosa Aneiros", Impossibilia, 11, pp. 125-148.

THOMPSON, John (2009). As novelas da memoria. Trauma e representación da historia na Galiza contemporánea. Vigo: Galaxia.

VILAVEDRA, Dolores (2018). "Singularidades da articulación socio-discursiva da narrativa galega de autoría feminina". En Maria Boguszewicz, Ana Garrido y Dolores Vilavedra (eds.), Identidade(s) e xénero(s) na cultura galega: unha achega interdisciplinaria. Varsovia: Instituto de Estudos Ibéricos e Iberoamericanos, pp. 167-194.

VILAVEDRA, Dolores (2011). "Guerra civil y literatura gallega", Cuadernos de la Revista internacional de estudios vascos, n. ${ }^{\circ} 8$, pp. 62-77.

VILAVEDRA, Dolores (2010). "Un esforzado labor compositivo”. Grial, n. ${ }^{\circ} 185$, pp. 91-92.

VILAVEDRA, Dolores (2009). "Na procura da identidade”, El País. «Luces», 2310-2009, p. 10.

Fecha de recepción: 3 de octubre de 2020.

Fecha de aceptación: 21 de diciembre de 2020. 